\title{
Characterization of Fine-grained Material Ejected by the Cotopaxi Volcano Employing X-ray Diffraction and Electron Diffraction Scattering Techniques
}

\section{Andrea V. Vaca ${ }^{1}$, Carlos R. Arroyo ${ }^{1^{*}}$, Alexis Debut ${ }^{1}$, Theofilos Toulkeridis ${ }^{2}$, Luis Cumbal ${ }^{1}$, Fernando Mato ${ }^{2}$, Mario Cruz D’Howitt ${ }^{3}$ and Eduardo Aguilera ${ }^{3}$}

${ }^{1}$ Centro de Nanociencia y Nanotecnología, Universidad de las Fuerzas Armadas ESPE, P.O. Box 171-5-231B, Sangolqui, Ecuador

${ }^{2}$ Departamento de Seguridad y Defensa, Universidad de las Fuerzas Armadas ESPE, P.O. Box 171-5-231, Sangolqui, Ecuador

${ }^{3}$ Departamento de Ciencias de la Tierra y Construcción, Universidad de las Fuerzas Armadas ESPE, P.O. Box 171-5-231, Sangolqui, Ecuador

"Corresponding author: Carlos R. Arroyo, Centro de Nanociencia y Nanotecnología, Universidad de las Fuerzas Armadas ESPE, P.O. Box 171-5-231B, Sangolqui, Ecuador, Tel: +593-23989400 Ext: 2113; E-mail: ccarroyo@espe.edu.ec

Received date: March 16, 2016; Accepted date: March 31, 2016; Published date: April 05, 2016

Copyright: (c) 2016 Vaca AV, et al. This is an open-access article distributed under the terms of the Creative Commons Attribution License, which permits unrestricted use, distribution and reproduction in any medium, provided the original author and source are credited.

\begin{abstract}
After 138 years of apparent silence, the Cotopaxi volcano awoke on August 14th of 2015 with a sequence of eruption events and the emission of both fine-grained volcanic material and gases. Four samples of the very first eruption were collected at different sites within the fallout area. The analysis of such samples, by using X-Ray Diffraction (XRD) as well as Electron Diffraction Scattering (EDS) techniques, allow us to determine the geochemical and mineralogical composition. On the basis of these results, together with the characterization and classification of the morphology of the collected fine-grained material, the presence of juvenile magma at the proximity of the crater has been categorically excluded. Therefore major eruptions and the subsequent generation of far-reaching lahars can be discarded for the duration of this volcanic stage.
\end{abstract}

Keywords: Cotopaxi volcano; Volcanic reactivation; Chemical composition of tephra; Characterization of ash particles; Granulometry

\section{Introduction}

The Cotopaxi volcano, located at the northern Andes in central Ecuador, is considered one of the most dangerous active volcanoes in the world [1]. This stratovolcano reaches $5897 \mathrm{~m}$ above sea level (ASL) and has a large story of frequent but minor volcanic events (Volcanic Explosivity Index; VEI = 1-2) and some less frequent but highly catastrophic eruptions (VEI = above 3) [2]. Based on the known eruptive history of the volcano over the last 2,200 years, the current probability of a severe eruptive event has been calculated to be of about $72 \%$. In the case of a major eruption, due to the significant increase of population and modern infrastructure in its surroundings, it would result in an enormously devastating human tragedy compared with past catastrophic events [1,2]. The lahar produced by the partial melting of its estimated $1 \mathrm{~km} 3$ glacier [3] would be one of the most destructive and lethal volcanic hazards. On August 14th of 2015, after 138 years of apparent tranquility, the Cotopaxi volcano got reactivated with a series of explosions, none above VEI $=1$. To understand the origin of this eruption and with the aim to assess if the event is a minor sporadic event or a potential catastrophic volcanic eruption, we have collected and analyzed the first material ejected by the Cotopaxi volcano the day of its reactivation [4].

\section{Materials and Methods}

Four samples from the very first eruption in the morning of the 14th of August 2015 were collected at different sites in the proximity of the
Cotopaxi volcano. The sampling method used has been described in [5-7] and the locations were chosen to cover the areas of highest probability of ash fallout: SAMPLE 1 collected in the campus of the Universidad de las Fuerzas Armadas-ESPE in Sangolqui, approximately at $41 \mathrm{~km}$ from the volcano; SAMPLE 2 from Cotogchoa, approximately at $34 \mathrm{~km}$; SAMPLE 3 from Machachi, approximately at $25 \mathrm{~km}$; and SAMPLE 4 from the crater of Cotopaxi volcano, collected at $5400 \mathrm{~m}$ height.

The Scanning Electron Microscope inspection was performed using a TESCAN FEG SEM MIRA3. To perform the SEM measurements, the fine-grained volcanic samples were fixed onto SEM stubs using a carbon adhesive layer and sputter-coated with an approximately $20 \mathrm{~nm}$ gold (99.99\% purity) layer. The chemical analysis was carried out by an EDS of the brand BRUKER model Quantax 200, installed in the SEM chamber and adetector XFlash 6130, reaching a resolution of $124 \mathrm{eV}$. In order to avoid inhomogeneity effects of the samples, a map of 100 points of EDS measurements was performed and averaged for each sample. Granularity was measured using the MIRA3 software capable of achieving a spatial resolution of $15 \mathrm{~nm}$. XRD studies were carried out using a PANalytical EMPYREAN setup within a $2 \theta$ configuration (generator-detector) X-ray tube copper $\mathrm{Ka} \lambda=1.54184 \AA$ and XCELERATOR detector (minimum angle step $0.0001^{\circ}$ ). To perform the XRD measurements the ash powder samples were directly deposited on optical microscope slides. The mineral composition of the samples was determined by using the PAN-ICDS database.

\section{Results}

\section{XRD analysis}


Citation: Vaca AV, Arroyo CR, Debut A, Toulkeridis T, Cumbal L, et al. (2016) Characterization of Fine-grained Material Ejected by the Cotopaxi Volcano Employing X-ray Diffraction and Electron Diffraction Scattering Techniques. Biol Med (Aligarh) 8: 280. doi: $10.4172 / 0974-8369.1000280$

Page 2 of 3

The optical inspection of the fine-grained material has determined that the mineral composition of the ejected material corresponds to a typical andesitic to dacitic component and rarely rhyodacitic composition. It has been also observed a high abundance of classical mineral composition of rocks like plagioclases, quartz, biotite, hornblende but also lithics, obsidian, pyrite and some other accessory minerals. The XRD analysis shows quite similar spectra for the four samples, as it is shown in Figure 1, which is associated to a mostly composition of plagioclase (Anorthite), next to quartz and other mainly felsic minerals. The slight differences between the spectra are associated with small differences in the high level or granularity of the samples.

\section{SEM analysis}

The SEM pictures, as those illustrated in Figure 2, demonstrate that the volcanic samples exhibit a highly fragmented structure. Moreover, the shape of the rock fragments and minerals ejected on the first eruptive event in the early morning of the 14th August as well as the fine-grained pyroclastic material of later explosions [8-10] have been exclusively characterized as fragmented and angular shaped. In none of the samples has been observed any vesiculated or porous materials with an origin of juvenile magma. The chemical analysis obtained by EDS measurements determined that the samples are rich in sulfur and contain abundant concentrations of iron, magnesium and manganese. These elements are homogenously distributed on all samples as it is illustrated in mapping pictures of Figure 3. The samples richest in sulfur were obtained in proximity to the volcano (less than $5 \mathrm{~km}$ ), while the ones having high contents in iron, magnesium and manganese were found at large distances from the crater (more than 5 $\mathrm{km}$ ). The iron found at large distances from the crater appears oxidized, most likely due to the exposition to the atmospheric oxygen.

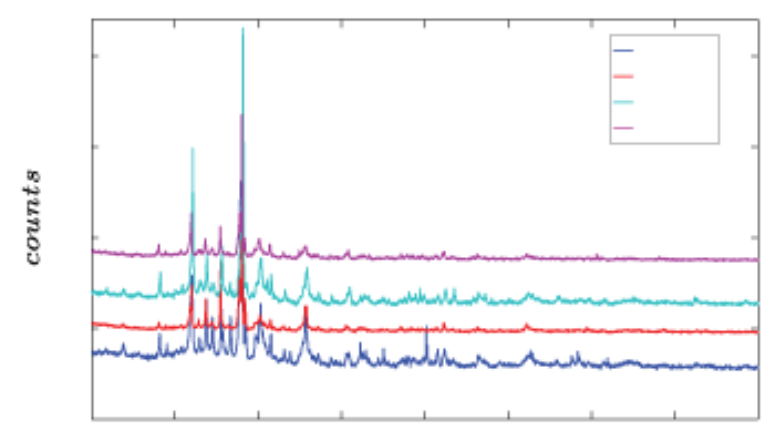

$2 \theta(\mathrm{deg})$

Figure 1: The XRD spectra from SAMPLE 1, 2, 3 and 4 showed similar features corresponding to a mostly composition of Anorthite Sodian composition. For claritythe spectra have been shifted 2000 units from SAMPLE 2 . The presence of magnetite in SAMPLE 1 is denoted as peaks around 50 (deg).
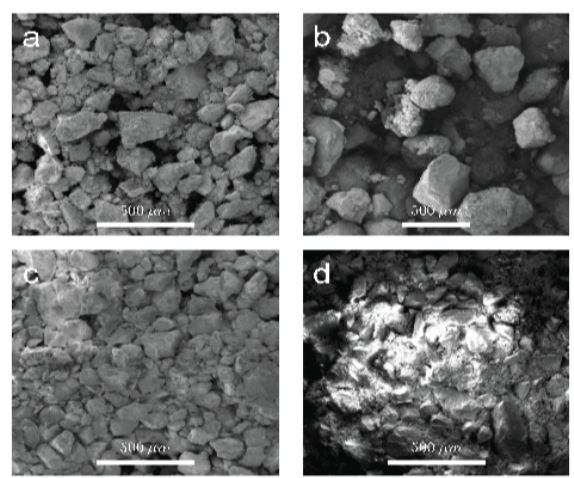

Figure 2: Representative SEM micrographs (Magnification 150X) obtained from (a)-(d) the SAMPLES 1, 2, 3 and 4 respectively. The images show mostly fragmented materials in all the samples analyzed.

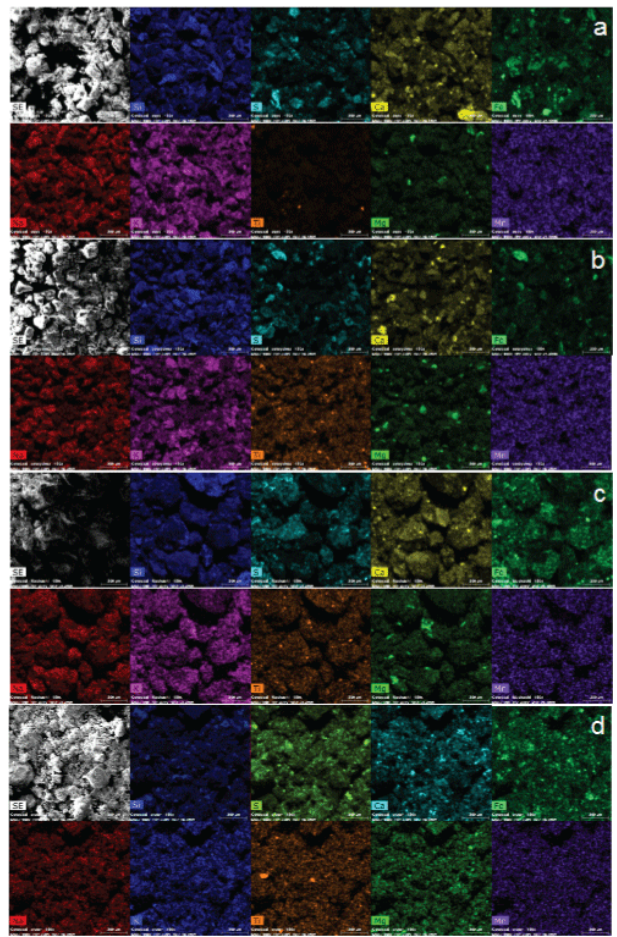

Figure 3: SEM-EDS maps (150X) showing the most abundant chemical elements obtained from (a-d) SAMPLE 1, 2, 3 and 4. From left to right and up to down the pictures correspond to: Topography (SE), Silicon (Si), Sulfur (S), Calcium (Ca), Iron (Fe), Sodium (Na), Potassium (K), Titanium (Ti), Magnesium ( $\mathrm{Mg}$ ) and Manganese (Mn).

\section{Discussion and Conclusion}

After decades of visual silence, the Cotopaxi volcano awoke with the emission of fine-grained volcanic material. The volcanic samples ejected by the Cotopaxi volcano were collected almost daily and 
Citation: Vaca AV, Arroyo CR, Debut A, Toulkeridis T, Cumbal L, et al. (2016) Characterization of Fine-grained Material Ejected by the Cotopaxi Volcano Employing X-ray Diffraction and Electron Diffraction Scattering Techniques. Biol Med (Aligarh) 8: 280. doi: $10.4172 / 0974-8369.1000280$

Page 3 of 3

nightly at different locations since its reactivation on August 14th [4,8-10]. By using Optical Microscopy, X-Ray Diffraction (XRD) as well as Scanning Electron Microscopy (SEM) and Electron Diffraction Scattering (EDS) techniques, we have determined the geochemical and mineralogical composition of the very first expelled material. The composition of the ejected material has been determined as typical andesitic to dacitic and rarely rhyodacitic composition with a high abundance of plagioclases, quartz, biotite, hornblende but also obsidian, pyrite and some other accessory minerals. Therefore, most of the collected material is felsic in composition, while the andesitic fragments came from later eruptions.

On the basis of our results, it can be concluded that such volcanic event of Cotopaxi volcano represents clearly a minor sporadic event rather than a severe eruptive phase. Therefore major explosions and the generation of far-reaching lahars is excluded for the time such volcanic phase. The information extracted from the composition and morphology of the fine-grained particles in almost real-time can be considered as fundamental information for understanding the mechanisms underlying the eruptive processes of volcanoes. Finally, we remark that this kind of studies could be used as a quick tool for the assessment of the volcanic activity and its threat to humans in the vicinity of the volcano.

\section{Acknowledgements}

Carlos R. Arroyo and Fernando Mato acknowledge support from the Prometeo Project of the National Secretariat of Higher Education, Science, Technology and Innovation (SENESCYT), Ecuador.

\section{References}

1. Aguilera E, Pareschi MT, Rosi M, Zanchetta G (2004) Risk from lahars in the northern valleys of Cotopaxi Volcano (Ecuador). Nat Hazards 33: 161-189.

2. Barberi F, Coltelli M, Frullani A, Rosi M, Almeida E (1995) Chronology and dispersal characteristics of recently (last 5000 years) erupted tephra of Cotopaxi (Ecuador): implications for long-term eruptive forecasting. J Volcanol Geoth Res 69: 217-239.

3. Mothes PA, Hall ML, Janda RJ (1998) The enormous Chillos Valley Lahar: an ash-flow-generated debris flow from Cotopaxi Volcano, Ecuador. Bulletin of Volcanology 59: 233-244.

4. Toulkeridis T, Arroyo CR, Cruz D'Howitt M, Debut A, Vaca AV, et al. (2015) Evaluation of the Initial Stage of the Reactivated Cotopaxi Volcano-Analysis of the First Ejected Fine-Grained Material. Nat Hazards 3: 6947-6976.

5. Toulkeridis T (2012) State of Volcanic Hazard Preparedness in Ecuador 2007-2012, in: Cities on Volcanoes 7 (COV7), Colima, Mexico.

6. Horwell CJ, Baxter PJ (2006) The respiratory health hazards of volcanic ash: a review for volcanic risk mitigation. Bulletin of Volcanology 69: $1-24$.

7. Witham CS, Oppenheimer C, Horwell CJ (2005) Volcanic ash-leachates: a review and recommendations for sampling methods. Journal of Volcanology and Geothermal Research 141: 299-326.

8. Vaca VA, Arroyo RC, Debut A, Toulkeridis T (2016) The 2015 Volcanic Activity of Cotopaxi Volcano. Ash Data Set 1: 1-213.

9. Vaca VA, Arroyo RC, Debut A, Toulkeridis T (2016) The 2015 Volcanic Activity of Cotopaxi Volcano. Ash Data Set 2: 1-213.

10. Vaca VA, Arroyo RC, Debut A, Toulkeridis T (2016) The 2015 Volcanic Activity of Cotopaxi Volcano. Ash Data Set 3: 1-205.
This article was originally published in a special issue, entitled: "Recent Advances in Biology \& Nanotechnology", Edited by Saurabh RamBihariLal Shrivastava 